\section{Self-fertility and Time of Stigma Receptivity in Styrax japonicum}

\author{
Sandra M. Reed ${ }^{1}$ \\ Floral and Nursery Plants Research Unit, U.S. National Arboretum, Agricultural \\ Research Service, U.S. Department of Agriculture, Tennessee State University \\ Nursery Crop Research Station, 472 Cadillac Lane, McMinnville, TN 37110
}

Additional index words. Japanese snowbell, hybridization, breeding, pollen tube growth, self-compatibility

\begin{abstract}
The objectives of this study were to evaluate self-fertility and to determine the effectiveness of pollinations made over a 4-day period in Japanese snowbell, $S$. japonicum Sieb. \& Zucc. Pollen germination and pollen tube growth were observed in stained styles following cross- and self-pollinations made from 1 day before to 2 days after anthesis. One month after pollination, fruit set averaged $40 \%$ in cross-pollinations and $14 \%$ in self-pollinations. Two months later, about one-third of the fruit resulting from cross-pollinations had aborted and only one fruit remained from the self-pollinations. This study demonstrated that stigmas of $S$. japonicum are receptive for at least 4 days and that flowers should be emasculated prior to making controlled cross-pollinations.
\end{abstract}

The genus Styrax is composed of $\approx 130$ species of deciduous or evergreen trees and shrubs (Krüssmann, 1984). Several species are cultivated, but Japanese snowbell (S.japonicum) is the most commercially significant. Native to Japan, China, Korea, Taiwan, and the Philippines, this small deciduous tree is hardy to U.S. Dept. of Agriculture (USDA) hardiness zone 5 (Dirr, 1998). Its most outstanding ornamental characteristic is the numerous small fragrant bell-shaped flowers that are produced in May to June. The flowers hang beneath the foliage in three- to six-flowered racemes, making the tree particularly attractive when viewed from below. Summer foliage is a lustrous medium to dark green and is generally free of insect and disease problems. The fruit is an ovoid drupe, containing one or two seeds. It may persist into late fall and early winter, but is of only minor ornamental interest. Growing to only $10 \mathrm{~m}$ in height, $S$. japonicum is an ideal tree for use under power lines and in small landscapes (Dirr, 1998; Meyer, 1992; Raulston, 1991).

A few cultivars of $S$. japonicum are commercially available in the United States (Dirr, 1998; Raulston, 1991). 'Issai' is a fast-growing selection that was introduced from Japan. Its popularity is based on its ease of rooting and rapid growth. A weeping form, 'Carillon', and a pink-flowered form, 'Pink Chimes', were also introduced from Japan. 'Emerald Pagoda' was collected off the southwest coast of Korea by the late J.C. Raulston during a U.S. National Arboretum expedition in 1985. Its leaves are two to four times larger than is typical for the species, and are dark green, thick, and leathery. The flowers are also considerably larger than

Received for publication 26 Dec. 2001. Accepted for publication 5 Aug. 2003. Mention of trade names of commercial products in the publication is solely for the purpose of providing specific information and does not imply recommendation or endorsement by the U.S. Dept. of Agriculture.

${ }^{1}$ Research Geneticist. usual. Other cultivars have been introduced to the United States, but are not currently commercially available.

Despite the outstanding ornamental characteristics of Styrax japonicum cultivars, they are not as widely utilized in the United States as are seed-grown plants of the species. Problems with branch dieback and lack of flowering have been reported for 'Carillon' and 'Pink Chimes' (Dirr, 1998; Meyer, 1992). We have frequently observed leaf and flower damage in these two cultivars and 'Emerald Pagoda' due to late spring freezes in middle Tennessee (USDA hardiness Zone 6b). Cultivars bred for use in Japanese gardens may not be fully adapted to the various climatic extremes encountered in U.S. landscapes.

Considerable morphological and physiological variability has been observed in seedling populations of $S$. japonicum (Meyer, 1992; Raulston, 1991). It may be possible to exploit this genetic variation to breed plants better suited to U.S. growing conditions than the cultivars currently available. However, little information concerning breeding systems and pollination biology of Styrax has been published. A study conducted with S. officinale subsp. redivivum (Sugden, 1986) indicated that fruit set was much higher when controlled cross-pollinations were made on the day flowers opened compared to pollinations made 1 $\mathrm{d}$ earlier or later. It took $\approx 3 \mathrm{~d}$ for pollen tubes to grow to the base of the styles in this species. No seed were obtained when $S$. officinale subsp. redivivum flowers were covered with bags to exclude insects, but pollen germination and pollen tube growth were not examined following self-pollinations. Reduced fruit set due to fruit abortion has been reported following self-pollination in S. obassia (Tamura and Hiura, 1998). Self-pollinated progeny of 'Carillon' were reported to exhibit a weeping plant habit (Raulston, 1991), but no details as to how the self-pollinations were made or their success rate were presented.

Information on the reproductive biology of $S$. japonicum is needed for use in genetic improvement programs. The objectives of this study were to evaluate self-fertility and to determine the effectiveness of pollinations made over a 4-d period in S. japonicum. Pollination effectiveness was assessed using fruit set and observations of pollen germination and pollen tube growth through styles.

\section{Materials and Methods}

Plant material and hybridization. Rooted cuttings from seven $S$. japonicum open-pollinated seedlings and 'Pink Chimes' were transplanted in June 2000 into 26.5-L containers. A single cutting from each of these eight plants was used in this study. Plants were grown in pine bark amended with $6.6 \mathrm{~kg} \cdot \mathrm{m}^{-3}$ 19N-2.1P-7.4K Osmocote fertilizer (ScottsSierra Horticultural Products Co., Maryville, Ohio), $0.6 \mathrm{~kg} \cdot \mathrm{m}^{-3}$ Micromax (Scotts-Sierra Horticultural Products Co.), and $0.2 \mathrm{~kg} \cdot \mathrm{m}^{-3}$ Epsom salts. Plants were grown under full sun in a $26-\mathrm{L}$ container in a pot-in-pot growing system and micro-irrigated using spray stakes during 2000 and 2001. Each plant was topdressed with $50 \mathrm{~g} 19 \mathrm{~N}-2.1 \mathrm{P}-6.6 \mathrm{~K}$ Osmocote fertilizer in Apr. 2001.

In early May 2001, all plants were brought into the greenhouse for controlled pollinations. Plants were kept in the greenhouse under natural daylengths for 1 month after pollinations. Mean daily temperatures in the greenhouse averaged $22{ }^{\circ} \mathrm{C}$, which was $3{ }^{\circ} \mathrm{C}$ higher than outside temperatures, during the period that the plants were kept indoors.

Individual branches bearing multiple flowers were selected and all open flowers removed. The branches were covered with Del-Net breathable plastic pollination bags (DelStar Technologies, Middletown, Del.). Flowers that were to be used as maternal parents and those that were to serve as pollen donors were allowed to reach anthesis under these protective bags.

Flowers to be used as maternal parents were emasculated $\approx 1 \mathrm{~d}$ prior to opening (anthesis), based on observations of flower color and size. All other flowers were removed from these branches and bags were placed back over the emasculated flowers. Pollinations were made using flowers that had opened within the prior $24 \mathrm{~h}$. For pollen collection, flowers were removed from the plant and held upright. The anthers were tapped lightly with a pair of fine-tipped forceps, causing large quantities of bright yellow-orange pollen to fall to the base of the flower. The anthers were then removed, and the stigmas of the maternal flowers touched directly to the collected pollen. Each stigma was examined using a $\times 2$-magnifying lens to ensure that pollen transfer had occurred. Bags were placed back over the branches where they remained for 2 weeks.

The seven $S$. japonicum plants originating from seed-grown material were used as maternal parents and for self-pollinations, while 'Pink Chimes' was used as the paternal parent in all cross-pollinations. Pollinations were made on the day of emasculation or 1,2 , or $3 \mathrm{~d}$ after emasculation. Since prior 
observations indicated that anther dehiscence occurs within a few hours of flower opening, the pollination times corresponded to $1 \mathrm{~d}$ prior to, the day of, and 1 and $2 \mathrm{~d}$ after expected anthesis and pollen shed. Pollination times were randomly distributed among maternal plants, with at least three plants used at each pollination time. All pollinations were made during a 9-d period beginning on 8 May 2001. With the exception of immature flowers that were on the same branches as the flowers that were pollinated, no other flowers were removed from the plants.

Observation of pollen tubes. For observation of pollen tubes, 110 flowers were emasculated. Twenty-five of the flowers were cross-pollinated $1 \mathrm{~d}$ after emasculation, while 10 flowers were cross-pollinated at each of the other three pollination times. Self-pollinations were made in a similar manner using the remaining 55 emasculated flowers. Five each of the cross- and self-pollinated flowers that were pollinated $1 \mathrm{~d}$ after emasculation were collected 1,4 , and $8 \mathrm{~h}$ after pollination. Five flowers were collected 24 and $48 \mathrm{~h}$ after pollination from cross- and self-pollinations made $0,1,2$, and $3 \mathrm{~d}$ after emasculation. An additional 10 flowers were emasculated but not pollinated; these were collected $2 \mathrm{~d}$ after emasculation.

Flowers were placed into FAA fixative (70\% 18 ethanol : 1 formalin : 1 glacial acetic acid)(Johansen, 1940) immediately following collection. After $24 \mathrm{~h}$ at room temperature in fixative, flowers were transferred to $70 \%$ ethanol, where they were stored for up to 5 months. Prior to staining, the style was excised at the point of attachment to the ovary and rinsed in distilled water. The style with attached stigma was softened using $8 \mathrm{~N} \mathrm{NaOH}$ for $4 \mathrm{~h}$. The tissue was rinsed in distilled water for $30 \mathrm{~min}$ prior to transfer to $0.1 \%(\mathrm{w} / \mathrm{v})$ aniline blue in $0.1 \mathrm{~N} \mathrm{~K}_{3} \mathrm{PO}_{4}$ for $1 \mathrm{~h}$ (Martin, 1959). The stigma and style were placed on a microscope slide in a drop of stain, squashed under a cover slip, and observed using an Olympus BX60 microscope (Olympus America, Melville, N.Y.) equipped with a $100-W$ high-pressure Hg lamp and an U-MNV near-ultraviolet (400-410 nm) filter. Callose plugs were observed as a yellow-green fluorescence and were used to detect growth of the pollen tubes through the styles.

Fruit and seed set. At each of the four pollination times, 50 cross- and 50 self-pollinations were made. An additional 50 flowers were emasculated and bagged, but not pollinated. For the self- and cross-pollinations, all flowers on a branch were enclosed in the same bag. Each pollination type $\times$ time of pollination treatment consisted of 4 to 7 bags of flowers; the number of flowers within a bag ranged from 3 to 24 . Number of fruit was counted 1 month after the pollinations were made. Number of fruit was recorded again $\approx 3$ months after pollination. For both time periods, percent fruit set inside each bag was calculated. Fruit were collected 15 weeks after pollinations were made, allowed to dry at $22^{\circ} \mathrm{C}$ for 2 to $3 \mathrm{~d}$, at which time the pericarps split open and the seed were collected.

\section{Results and Discussion}

Observations of pollen tubes. Styrax japonicum styles were observed to have a central pore through which the germinating pollen tubes grew. These open styles made measurements of pollen tube length difficult as pollen tubes often became displaced during squashing. In addition, while no pollen grains were observed on the stigmas of the emasculated, unpollinated flowers, considerable fluorescence was observed throughout the stylar tissue. While it was easy to distinguish between this background fluorescence and the fluorescence from callose plugs in pollen tubes using higher magnifications $(\times 200)$, the presence of background fluorescence interfered with pollen tube length measurements. Consequently, pollen tube penetration through the style was recorded not as actual pollen tube lengths but as general observations as to how far down the styles the pollen tubes and fluorescent callose plugs were observed.

Germinating pollen grains were observed on stigmas of flowers cross-pollinated on the day of anthesis and collected $1 \mathrm{~h}$ after pollination (Fig. 1A). By $4 \mathrm{~h}$ after pollination, pollen tubes had elongated (Fig. 1B) and penetrated the style. Callose plugs were observed in the upper half of styles collected and fixed $8 \mathrm{~h}$ after pollination (Fig. $1 \mathrm{C}$ and D). Similar findings at each of the collection times were observed following self-pollinations. Callose plugs were observed at the base of styles collected 24 and $48 \mathrm{~h}$ from flowers that had been self- or cross-pollinated $0,1,2$, and $3 \mathrm{~d}$ after emasculation.

Among individual styles, number of callose plugs and pollen tubes varied; however, all of the styles examined in this study showed evidence of pollen germination and/or pollen tube growth. The bright color of the S. japonicum pollen allowed visual verification that pollen
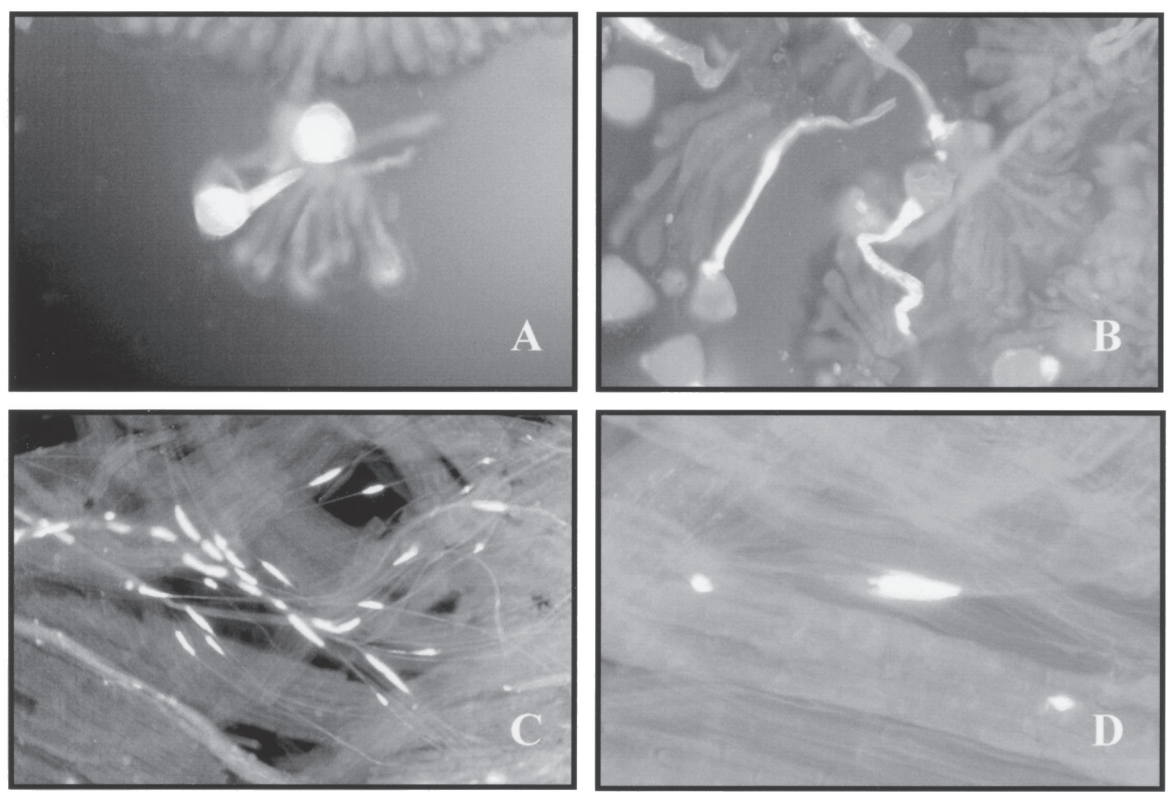

Fig. 1. Pollen germination and pollen tube growth in Styrax japonicum styles stained with aniline blue and viewed using fluorescence microscopy. (A) Germinating pollen grains on surface of stigma, $1 \mathrm{~h}$ after pollination. (B) Pollen tube elongation on surface of stigma, $4 \mathrm{~h}$ after pollination. (C) Multiple pollen tubes in stylar tissue, $8 \mathrm{~h}$ after pollination. (D) Close-up of callose plug in stylar tissue, $8 \mathrm{~h}$ 
Table 1. Fruit set of cross- and self-pollinations of Styrax japonicum made over a 4-d period.

\begin{tabular}{lccc}
\hline Type of & Time of & \multicolumn{2}{c}{ Crosses setting fruit (\%) } \\
\cline { 2 - 4 } pollination & pollination & $24.3 \pm 10.6$ & $19.7 \pm 6.8$ \\
\hline Cross & 1 d prior to anthesis & $30.3 \pm 8.6$ & $20.5 \pm 8.4$ \\
Cross & day of anthesis & $46.2 \pm 18.3$ & $21.2 \pm 7.9$ \\
Cross & 1 d after anthesis & $47.5 \pm 16.7$ & $24.7 \pm 5.1$ \\
Cross & 2 d after anthesis & $1.0 \pm 1.0$ & $1.0 \pm 1.0$ \\
Self & 1 d prior to anthesis & $21.8 \pm 15.0$ & 0 \\
Self & day of anthesis & $21.6 \pm 12.6$ & 0 \\
Self & 1 d after anthesis & $4.5 \pm 4.5$ & 0 \\
Self & 2 d after anthesis & months after pollination \\
\hline
\end{tabular}

${ }^{2}$ Mean \pm SE. Pollinations were grouped into 4 to 7 bags per treatment, with each bag having 3 to 24 flowers. A total of 50 flowers/treatment were pollinated.

had abscised by 3 months after pollination. The final percentage of fruit set among crosspollinations was again fairly constant across the pollination times. Only one fruit resulting from self-pollinations was present when the second fruit count was made. Each cross- and self-pollinated fruit contained one seed, which is typical of $S$. japonicum even though ovaries usually contain 16 to 24 ovules (Dirr, 1995; Perkins, 1907).

A low fruit: flower ratio has been observed in many plant species. Factors responsible for this phenomenon have been extensively reviewed by Stephenson (1981). While low fruit set may be the result of a lack of pollinator attraction in native stands, the number of female flowers usually exceeds fruit set even when all flowers are pollinated. Many species initiate far more fruit than are developed to maturity. In most species, abscission of "surplus" fruit occurs in one or more distinct periods of abortion that precede the rapid growth phase of the fruit. While most abortions of undamaged fruit seem to be due to resource limitation, undamaged juvenile fruit may abscise because of genetic or developmental abnormalities. Selective abortion of fruit from self-pollinated flowers has been noted in several species (Bushnell, 1920; Haber, 1928; Murneck, 1954).

Styrax japonicum fruit counts that were made 1 month after pollination indicated that only $35 \%$ of the cross-pollinations and $14 \%$ of the self-pollinations had set fruit. By 3 months after pollination, fruit was observed from only $23 \%$ of the cross-pollinations and less than $1 \%$ of the self-pollinations. It is possible that a higher percentage of fruit set would have been recorded from both the cross- and self-pollinations of $S$. japonicum if fruit counts had been made sooner than 1 month after pollination. In S. obassia native stands, the number of fruit per inflorescence decreased from 3.2 at 2 weeks after flowering, to 1.9 at 6 weeks after flowering, and to 1.6 by 10 weeks after flowering (Kato and Hiura, 1999). Removing all flowers that were not used in controlled pollinations to prevent open-pollinated seed from developing and competing for resources may also have increased the percentage of successful controlled pollinations.

In summary, $S$. japonicum stigmas appear to be receptive from at least $1 \mathrm{~d}$ before to $2 \mathrm{~d}$ after anthesis. From a practical viewpoint, this indicates that all flowers on a branch that appear to be within 1 to $4 \mathrm{~d}$ of anthesis can be emasculated at the same time, covered with a protective bag, and pollinated $3 \mathrm{~d}$ later. Bulk pollinations and emasculations save time and reduce mechanical injury problems associated with covering and uncovering flowers. Despite the fact that pollen tubes grew down all of the styles that were microscopically examined, low seed and fruit set were recorded following both cross- and self-pollination. This, along with the reduction in fruit numbers that occurred between 1 and 3 months after pollination, indicates fruit abortion occurs in S.japonicum. If fruit resulting from self-pollinations is selectively aborted in this species, greater quantities of self-seed might be obtained by isolating plants during flowering so that only self-pollinations occur. Microscopic evidence of pollen germination and pollen tube growth following self-pollination, supported by a prior report of self-fertility in one $S$. japonicum cultivar, indicate that $S$. japonicum flowers should be emasculated when making cross-pollinations if exclusion of self-progeny is desired.

\section{Literature Cited}

Bushnell, J.W. 1920. The fertility and fruiting habit in Cucurbita. Proc. Amer. Soc. Hort. Sci. 15:47-51.

Dirr, M.A. 1998. Manual of woody landscape plants. Stipes Publ., Champaign, Ill.

Perkins, J. 1907. Styracaceae. Das pflanzenreich, IV, 241:1-111.

Haber, E.S. 1928. Inbreeding the table green (Des Moines) squash. Proc. Am. Soc. Hort. Sci. 25: 111-114.

Johansen, D.A. 1940. Plant microtechnique. McGraw-Hill. New York.

Kato, E. and T. Hiura. 1999. Fruit set in Styrax obassia (Styracaceae): The effect of light availability, display size, and local floral density. Am. J. Bot. 86:495-501.

Krüssmann, G. 1984. Manual of cultivated broadleaved trees and shrubs. Vol. 1. Timber Press, Beaverton, Ore.

Martin, F.W. 1959. Staining and observing pollen tubes in the style by means of fluorescence microscopy. Stain Technol. 34:125-128.

Meyer, P. 1992. The snowbells of Korea. Arnoldia 52:2-8.

Murneck, A.E. 1954. The embryo and endosperm in relation to fruit development, with special reference to the apple, Malus sylvestris. Proc. Amer. Soc. Hort. Sci. 64:573-582.

Raulston, J.C. 1991. Styrax evaluations in the NCSU Arboretum. 36:305-310.

Stephenson, A.G. 1981. Flower and fruit abortion: Proximate causes and ultimate functions. Ann. Rev. Ecol. Syst. 12:253-279.

Sugden, E.A. 1986. Anthecology and pollinator efficacy of Styrax officinale subsp. redivivum (Styracaceae). Amer. J. Bot. 73:919-930.

Tamura, S. and T. Hiura. 1998. Proximate factors affecting fruit set and seed mass of Styrax obassia in a masting year. Ecoscience 5:100-107. 